\title{
Review Article \\ Treatment of Nonalcoholic Steatohepatitis in Adults: Present and Future
}

\author{
S. Gitto, ${ }^{1}$ G. Vitale, ${ }^{2}$ E. Villa, ${ }^{1}$ and P. Andreone ${ }^{2}$ \\ ${ }^{1}$ Dipartimento di Gastroenterologia, Azienda Ospedaliero-Universitaria and Università di Modena e Reggio Emilia, \\ 41125 Modena, Italy \\ ${ }^{2}$ Dipartimento di Scienze Mediche e Chirurgiche, Università di Bologna e Dipartimento dell'Apparato Digerente, \\ Azienda Ospedaliero-Universitaria di Bologna, Policlinico Sant'Orsola Malpighi, 40138 Bologna, Italy
}

Correspondence should be addressed to P. Andreone; pietro.andreone@unibo.it

Received 4 February 2015; Accepted 5 March 2015

Academic Editor: Eldon A. Shaffer

Copyright (C) 2015 S. Gitto et al. This is an open access article distributed under the Creative Commons Attribution License, which permits unrestricted use, distribution, and reproduction in any medium, provided the original work is properly cited.

\begin{abstract}
Nonalcoholic steatohepatitis has become one of the most common liver-related health problems. This condition has been linked to an unhealthy diet and weight gain, but it can also be observed in nonobese people. The standard of care is represented by the lifestyle intervention. However, because this approach has several limitations, such as a lack of compliance, the use of many drugs has been proposed. The first-line pharmacological choices are vitamin E and pioglitazone, both showing a positive effect on transaminases, fat accumulation, and inflammation. Nevertheless, vitamin E has no proven effect on fibrosis and on long-term morbidity and mortality and pioglitazone has a negative impact on weight. Other drugs have been studied such as metformin, ursodeoxycholic acid, statins, pentoxiphylline, and orlistat with only partially positive results. Among the emerging treatments, telmisartan is particularly interesting as it seems to have an impact on insulin resistance, liver steatosis, inflammation, and fibrosis. However, the pathogenesis of steatohepatitis is highly complex and is determined by different parallel hits; indeed, the association of different drugs that act on various levels has been suggested. In conclusion, lifestyle intervention should be optimised and the associations of different drugs should be tested in large studies with long-term outcomes.
\end{abstract}

\section{Introduction}

1.1. Definition and Aim. We define "nonalcoholic fatty liver disease (NAFLD)" as hepatic steatosis that accounts for more than $5-10 \%$ of the total hepatic weight. To make an accurate diagnosis, imaging or histological techniques are necessary, and other causes of fat accumulation should be excluded such as the excessive consumption of alcohol (women $\leq 20 \mathrm{~g} / \mathrm{d}$, men $\leq 30 \mathrm{~g} / \mathrm{d}$ ). Moreover, other causes of secondary macrovesicular steatosis should be explored such as parenteral nutrition, hepatitis C, Wilson's disease, states of hunger, lipodystrophy, abetalipoproteinemia, and drugs (e.g., methotrexate, amiodarone, and steroids). Furthermore, clinicians should search for other origins of microvesicular steatosis such as Reye's syndrome, acute fatty liver of pregnancy, HELLP syndrome, metabolic disorders (e.g., lecithincholesterol-acyltransferase deficiency), and the use of drugs (e.g., antiretroviral drugs or valproate) [1].
Notably, NAFLD is considered to be the hepatic manifestation of metabolic syndrome, as it is strongly associated with insulin resistance (IR), central obesity, reduced glucose tolerance, type 2 diabetes mellitus (T2DM), arterial hypertension, and hypertriglyceridaemia [2].

However, when we refer to NAFLD, a wide spectrum of disorders is included, ranging from simple nonalcoholic fatty liver (NAFL) to nonalcoholic steatohepatitis (NASH); these disorders are characterised not only by an inflammatory condition, ballooning degeneration, necroapoptosis, and fibrosis but also by a relevant impact on morbidity and mortality [1].

In this review, we analyse the relationship between the complex molecular aspects of NASH and the most interesting and promising treatment options. The literature search included published articles (peer-reviewed original, review, and meta-analyses) with a strong priority for randomised controlled trials (RCT). The search terms included "NAFLD and therapy," "NASH and therapy," "NAFLD and treatment," 
"NASH and treatment," "NAFLD and drug," and "NASH and drug."

1.2. Epidemiology. In the last several years, NAFLD has continued to increase worldwide and is the most common reason for irregular liver tests in both developed and emerging countries [3]. Today, in both Europe and the United Kingdom, NAFLD represents the most frequent cause of chronic liver disease $[4,5]$. It was reported that NASH affects approximately $1 \%$ of the European and North-American population, and longitudinal studies demonstrated that the histological patterns worsen in approximately one-third of patients who are at risk of progression to cirrhosis [6]. In the United States (US), according to the "National Health and Nutrition Examination Survey," the proportion of NAFLD among chronic liver diseases increased from $47 \%$ to $75 \%$ between 1988 and 2008. The rationale for this increase is most likely an increase in metabolic risk factors. In fact, in the same time period, the prevalence of obesity, visceral obesity, T2DM, IR, and arterial hypertension increased [7], and it is well known that patients with NAFL are also more likely to be obese (from $30 \%$ to $100 \%$ ) and have T2DM (from $10 \%$ to 75\%) [7].

According to the "Organization for Economic Cooperation and Development," in 2000, $11.5 \%$ of German adults were obese, while ten years later, the percentage increased to $14.7 \%$ [8]. It was also reported that, in Europe, approximately onethird of adults exhibit a pattern of NAFLD [5]. The prevalence ranges between $13.9 \%$ and $26.6 \%$ and is based on whether the newest technology (i.e., ultrasound) is used in the screening [9]. However, if we analyse several subgroups such as patients who are affected by T2DM, we find that $44 \%$ of patients exhibit a pattern reminiscent of NAFLD [5]. Interestingly, for reasons that are not completely clear, an increase in the prevalence of NAFLD was recently cited among younger (e.g., $12.8 \%$ in Australia) and older people (35\% in Netherlands) $[10,11]$.

When the attended variance that is related to the diagnostic methods is considered in the available studies, the global prevalence of NAFLD ranges from $6 \%$ to $33 \%$, while the prevalence of NASH is notably lower $(3 \%-5 \%)$ [12].

Although many epidemiological studies have shown that NAFLD is strictly connected to an unhealthy diet and sedentary behaviours [13], metabolic liver disease can also be found in nonobese populations [14]. Specifically, Caldwell et al. [15] reported that both ethnicity and genetic polymorphisms could play a central role in the development of this disease.

1.3. Molecular Aspects. Traditionally, the pathogenesis of NAFLD was conceived as a "two-hit" process [16]: (a) the accumulation of lipids in hepatocytes promotes IR, which is the key factor for the development of hepatic steatosis; (b) the consequences are an increase in proinflammatory cytokines and adipokines, mitochondrial dysfunction, oxidative stress, and endoplasmic reticulum stress, which lead to hepatocyte injury, inflammation, and fibrosis. In the past few years, many authors $[17,18]$ have reported that NASH is associated with a significantly worse outcome with respect to simple steatosis. Indeed, it has been suggested that NASH and simple steatosis should be considered two separate diseases. After consideration of the progressive form of NAFLD, which is definitively represented by NASH, a new and more realistic model was proposed: the "multiparallel hits" hypothesis [19]. The main concept that has emerged from this new idea is that different events occur that in turn determine liver damage, but these events take place in parallel, not consecutively. Remarkably, all of the events that favour the pathogenesis of NASH are potentially therapeutic targets. We can consider the following elements as the main pathological protagonists: IR, oxidative stress, gut, adipose and pancreas tissues, altered lipid metabolism, bile acids, gut microbiota, and bacterial endotoxins. It is important to underline that all the mechanisms of damage that are involved in the pathogenesis of NASH enhance two conditions that are central in the progression of NASH: IR and systemic chronic inflammation. The molecular basis of IR is the result of both genetic and nongenetic mechanisms. However, IR initiates a vicious circle that leads to inflammation, hypercoagulability, and atherogenesis. Interestingly, IR develops in the vasculature earlier than in muscle, liver, or adipose tissue, and this explains the high cardiovascular risk that can be found in patients with IR [20]. Tumour necrosis factor-alpha (TNF- $\alpha$ ) plays an important role in the development of an inflammatory state, determines apoptotic and fibrogenic reactions, and regulates IR [21]. In addition, oxidative stress is considered to be an important stage in the development of NASH. Oxidative stress is due to mitochondrial dysfunction and represents a true turning point for many investigators. The loss of electrons from complexes I and III in the mitochondrial electron transport chain can combine with oxygen, which generates reactive oxygen species; these promote damage to the DNA, lipid membranes, and proteins $[22,23]$. Inflammatory mediators that are derived from various tissues such as gut and adipose tissue seem to play a role in the cascade of inflammation and fibrosis of NASH. Within the adipose and liver tissues, increased lipid storage, lipogenesis, and (adipo)cytokine synthesis occur as stress signals for the endoplasmic reticulum (ER). Interestingly, altered adipokine profiles have been suggested to play a pivotal role in the progression of NASH [24]. Glucosedependent insulinotropic peptide (GIP) and glucagon-like peptide-1 (GLP-1) are incretin hormones that are released by the gastrointestinal tract in response to nutrients. The impairment of incretins, which is observed classically in T2DM, seems to have a role in the development of NASH because it enhances IR and fat accumulation [25]. Bile acids are other significant regulators of glucose homeostasis through many signalling pathways that regulate the metabolism of both glucose and cholesterol. Notably, in conditions such as T2DM, the composition of bile acids is altered and a decrease in the secretion of bile in the gut is observed; consequently, a reduction in the secretion of GLP-1 and impairment of glucose homeostasis may occur. Remarkably, patients with NAFLD can show a hyperinsulinemic state that definitively promotes lipogenesis and hepatic lipid deposition and may also accelerate the development of liver disease [26, 27]. Many authors have suggested a significant connection between altered cholesterol homeostasis and hepatic free 
cholesterol accumulation as a prompt for the pathogenesis of NASH $[28,29]$. Altered lipid metabolism is one of the main stages of the pathogenesis of NASH, which leads to the accumulation of intermediate products such as diacylglycerol and phospholipids (e.g., sphingolipids and ceramides); these are directly associated with fatty acid-induced toxicity and IR. These metabolites promote the activation of many kinases that negatively regulate the insulin pathway [30]. Indeed, the accumulation of free cholesterol in the ER membrane decreases its fluidity and determines cellular stress and apoptosis [31, 32]. The role of gut microbiota in the pathogenesis of NASH has generated a growing interest as modifications in its composition could increase the permeability of the gut and the translocation of bacterial endotoxins, which may promote systemic inflammation and IR [33]. Bacterial endotoxins, such as lipopolysaccharide (LPS), are a significant cause of hepatic neutrophil infiltration in the NASH subjects [34]. Even if the LPS seems to have a relevant role in the pathogenesis of NASH, the underlying mechanisms are uncertain. Imajo et al. [35], through a mice-model study, demonstrated that the upregulation of CD14 in Kupffer cells by leptin-mediated signaling can determine hyperreactivity against the endotoxins. Indeed, the authors showed that hyperresponsivity against low-dose LPS, typically found in the high-fat diet mice, can favour the NASH progression, in terms of both inflammation and fibrosis.

\section{Standard of Care: Lifestyle Interventions}

NAFLD and NASH are linked to excess body weight, an unhealthy diet, and inactive behaviours [13, 36, 37]. Notably, disease progression from NAFL to NASH is basically stated by obesity, T2DM, and metabolic syndrome, all of which are associated with unhealthy activities [13]. According to this view, all guidelines concur that lifestyle modifications are the first-line approach to manage patients with NAFLD and NASH [38-41]. However, while diet and exercise guidelines for conditions such as T2DM and cardiovascular disease are well established, no guidelines exist that indicate the ideal diet and exercise modalities. Nevertheless, it is well known that lifestyle coaching should involve a personalised diet, physical activity, and cognitive-behaviour therapy [42]. In fact, diet and physical activity could support weight loss, the recovery of liver enzymes, and an improvement in histological alterations [43].

According to Promrat et al. [44], who reported interesting data from a RCT, the main targets in patients who are affected by NASH come from the "US Diabetes Prevention Program" and are a weight loss of $7 \%$ and 150 minutes/week of physical activity [45]. The authors enrolled patients with NASH and evaluated the effects of lifestyle intervention using a combination of diet, exercise, and behaviour therapy. After 48 weeks of treatment, patients who received a lifestyle intervention lost an average of $9.3 \%$ of their weight versus $0.2 \%$ in the controls and demonstrated a significant reduction in "NAFLD activity score." Moreover, the score improvement correlated significantly with weight reduction. In fact, a weight loss of $7 \%$ significantly decreased fat accumulation and improved necroinflammation even if a significant effect on fibrosis was not shown [44]. In a meta-analysis in 2010, Musso et al. [46] confirmed that significant weight loss is safe and leads to better histological and metabolic parameters in patients with NASH. In particular, a 5\% weight loss seems to decrease liver steatosis and to ameliorate metabolic parameters, but higher weight loss is likely necessary to downgrade the necroinflammation and the overall disease activity. Notably, a gradual weight loss $(<1.6 \mathrm{~kg} /$ week) should be recommended because faster weight loss might worsen the liver injury [47]. Eckard et al. [48] conducted a RCT that involved 56 patients with a biopsy-proven diagnosis of NAFLD. Subjects were assigned to 1 of 4 lifestyle modification subgroups for 6 months: standard care, low-fat diet and moderate exercise, moderatefat/low-processed-carbohydrate diet and moderate exercise, or moderate exercise only. All subgroups demonstrated a decrease in the "NAFLD activity score" over the 6-month period with no significant difference between the subgroups. In addition, in all groups a significant decrease was observed in the Brunt grade and in the levels of ALT and AST. Among patients with NASH at baseline, 53\% improved their Brunt grade or stage classification, and $25 \%$ had no criteria for $\mathrm{NASH}$ at 6 months. Interestingly, no subgroup showed a relevant weight loss greater than $5 \%$. In this regard, physical activity, if characterised by aerobic and resistance training, shows an independent positive effect in the decrease of fat in the liver, regardless of the weight loss $[49,50]$. Moreover, it should be considered that patients with NAFLD/NASH are often at a high cardiovascular risk, and physical activity, which is expected to improve cardiorespiratory fitness, is important to decrease this hazard [51, 52]. In a thorough review and analysis, Peng et al. [53] reported that the available data are not enough to draw any conclusive results on the proper lifestyle programme and that RCTs are necessary for the evaluation of the beneficial and harmful effects of weight reduction.

Centis et al. [42] analysed the motivation of patients with metabolic liver disease when they changed their habits. The authors demonstrated that a large number of subjects experienced an inadequate inclination to change, particularly with regard to physical activity. This low level of readiness highlights the importance of the use of individually tailored techniques. Notably, in this context, behavioural counselling represents a central part of the therapeutic approach as it affords patients with the information, self-efficacy, critical thinking skills, and tools to realise a better lifestyle so that their prognosis improves.

The lifestyle approach has at least two limits: the compliance of the patients and the difficulty to present a unique and clear scientific vision. In fact, lifestyle modifications can be difficult to put into practice by the patient due to lack of compliance or physical disability. Still, the best solution in terms of nutrients for weight decrease and maintenance remains unclear. Many accessible studies do not report nutrient intake or physical activity and only record little patient information. Studies of the lifestyle interventions in patients with NAFLD/NASH show significant heterogeneity in the enrolled subjects, and, thus, they report limited details on the adherence to the lifestyle changes [54]. For all of 
TABLE 1

\begin{tabular}{|c|c|c|c|c|c|c|c|}
\hline \multirow{2}{*}{ Effects on } & \multirow{2}{*}{ Weight loss } & \multirow{2}{*}{ IR } & \multirow{2}{*}{ AST/ALT } & \multicolumn{2}{|c|}{ Histology } & \multirow{2}{*}{$\begin{array}{c}\text { Long-term } \\
\text { morbidity }\end{array}$} & \multirow{2}{*}{$\begin{array}{c}\text { Long-term } \\
\text { mortality }\end{array}$} \\
\hline & & & & Inflammation & Fibrosis & & \\
\hline Lifestyle interventions & Yes & Yes & Yes & Yes & Unproven & Unproven & Unproven \\
\hline
\end{tabular}

TABLE 2

\begin{tabular}{lccccccc}
\hline Effects on & Weight loss & IR & AST/ALT & Histology & Long-term & $\begin{array}{c}\text { Long-term } \\
\text { mortality }\end{array}$ \\
\hline Vitamin E & No & No & Yes & Yes & No & Unproven & Unproven \\
\hline
\end{tabular}

these reasons, more scientific energy should be devoted to the improvement of this strong therapeutic tool (see Table 1).

\section{First-Line Drug: Vitamin E}

Vitamin E (RRR- $\alpha$-tocopherol) is an important lipid-soluble antioxidant that is able to scavenge free radicals and avoid lipid peroxidation. In recent years, the therapeutic effects of vitamin E supplementation on NAFLD and NASH have been investigated [55-57], and today, vitamin E should be considered as a first-line pharmacotherapy for patients with biopsy-proven NASH who do not have diabetes. On the contrary, vitamin $\mathrm{E}$ is not recommended for the treatment of NASH in diabetic patients, or in cases of NAFLD without liver biopsy, NASH with cirrhosis, or cryptogenic cirrhosis [41].

In a recent meta-analysis, Ji et al. [58] reported that vitamin $\mathrm{E}$ supplementation might improve transaminase levels in patients with NASH, which confirms the therapeutic potential of vitamin E [58]. Sanyal et al. [56] developed what is certainly the most relevant RCT with regard to the use of vitamin $\mathrm{E}$ in patients with NASH. In their trial of pioglitazone versus vitamin E versus placebo in which 247 adults with NASH were enrolled, vitamin E supplementation (800 IU daily) for 96 weeks significantly improved steatosis and inflammation and resolved the ballooning seen in adult patients with NASH who have aggressive disease. Specifically, patients in the vitamin E arm showed a significantly better histological improvement compared with those who received the placebo. The transaminase level was decreased in patients if it is assumed that both vitamin $\mathrm{E}$ and pioglitazone were connected to the reductions of hepatic steatosis and lobular inflammation. Notably, neither vitamin E nor pioglitazone was associated with a significant improvement in fibrosis, and pioglitazone led to an increase in weight compared with vitamin E or placebo.

Validation is needed for the use of vitamin $\mathrm{E}$ in children, and long-term RCTs are required to assess the long-term efficacy and safety of vitamin E [59]. Finally, it should be mentioned that a published meta-analysis [60] has suggested that a high dose of vitamin $\mathrm{E}$ (>400 IU daily) may increase the risk for all-cause mortality. Nevertheless, in this meta-analysis, which included 19 trials, high-dosage trials ( $\geq 400 \mathrm{IU} / \mathrm{d}$ ) were smaller, on average, compared with others, and the studied population was not homogeneous (see Table 2).

\section{Second-Line Option: Pioglitazone}

As IR is a well-known hallmark in the pathogenesis of $\mathrm{NASH}$, thiazolidinediones (pioglitazone and rosiglitazone) were reported as possible therapeutic options.

Sanyal et al. [56] previously reported that pioglitazone can lead to a decrease in AST and ALT levels and, from a histological point of view, can decrease steatosis and lobular inflammation. Other authors had previously described the effects of pioglitazone on NASH with partial and doubtful results. In two small, noncontrolled studies, Promrat et al. and Lutchman et al. [61, 62] suggested that 48 weeks of pioglitazone ( $30 \mathrm{mg} /$ day) may improve NASH both biochemically and histologically. However, they also reported that weight gain is a major side effect of the long-term use of the pioglitazone and that this may significantly limit its use. Through two stronger, double-blind RCTs, Belfort et al. [63] and Aithal et al. [64] demonstrated that pioglitazone (45 mg daily for 24 weeks in the first study and $30 \mathrm{mg}$ daily for 48 weeks in the second) not only caused weight gain but also enhanced tissue inflammation and fibrosis. In 2011, Musso et al. [65] reported that pioglitazone could positively improve liver histology and the cardiometabolic profile in the context of NASH, but it also demonstrated the same impact with respect to weight loss.

With regard to rosiglitazone, in 2008, Ratziu et al. [66] published a RCT that suggested that the positive effect of this drug on the AST/ALT levels and on liver steatosis led to weight gain but had no significant effect on fibrosis.

In 2012, a meta-analysis on the use of pioglitazone and rosiglitazone in the treatment of NASH was performed [67]. The authors reported that thiazolidinediones might decrease ALT levels and improve histological parameters and that pioglitazone might reverse fibrosis in NASH; however, this latter effect represents the most important point of interest.

According to a recently published review article that was conducted by an expert panel from the "Chilean Gastroenterological Society" and the "Chilean Hepatology Association" [68], pioglitazone together with vitamin $\mathrm{E}$ is a proven pharmacological choice for patients with biopsyproven NASH, although evidence on its long-term safety and efficacy is lacking. Additionally, the guidelines of the American Association for the Study of Liver Diseases [41] indicate pioglitazone as a possible therapeutic drug for the 
TABLE 3

\begin{tabular}{|c|c|c|c|c|c|c|c|}
\hline \multirow{2}{*}{ Effects on } & \multirow{2}{*}{ Weight loss } & \multirow{2}{*}{ IR } & \multirow{2}{*}{ AST/ALT } & \multicolumn{2}{|c|}{ Histology } & \multirow{2}{*}{$\begin{array}{c}\text { Long-term } \\
\text { morbidity }\end{array}$} & \multirow{2}{*}{$\begin{array}{c}\text { Long-term } \\
\text { mortality }\end{array}$} \\
\hline & & & & Inflammation & Fibrosis & & \\
\hline Pioglitazone & Opposite & Yes & Yes & Yes & Yes & Unproven & Unproven \\
\hline
\end{tabular}

TABLE 4

\begin{tabular}{lccccccc}
\hline Effects on & Weight loss & IR & AST/ALT & $\begin{array}{c}\text { Histology } \\
\text { Inflammation }\end{array}$ & $\begin{array}{c}\text { Long-term } \\
\text { Fibrosis }\end{array}$ & $\begin{array}{c}\text { Long-term } \\
\text { morbidity }\end{array}$ \\
\hline Metformin & Yes & Yes & No & No & No & Unproven & Unproven \\
\hline
\end{tabular}

TABLE 5

\begin{tabular}{lccccccc}
\hline Effects on & Weight loss & IR & AST/ALT & Histology & Inflammation & Fibrosis & $\begin{array}{c}\text { Long-term } \\
\text { morbidity }\end{array}$ \\
\hline UDCA & No & No & No & Yes & No & Unproven & Unproven \\
\hline
\end{tabular}

treatment of NASH. However, the vast majority of patients enrolled in the available studies did not have a diagnosis of T2DM, and, therefore, data about its long-term efficacy and safety are not available (see Table 3 ).

\section{Broken Promises}

5.1. Metformin. It is well known that metformin can positively affect IR, which is a cornerstone of the pathogenesis of NASH. Consequently, the possible role of this drug in the treatment of metabolic liver disease has been extensively studied. In 2004, Nair et al. [69] published a small openlabel trial and reported that a three-month therapy with metformin was able to decrease the levels of ALT/AST but that this positive effect was only transitory. Remarkably, the authors reported a lack of significant improvement in both liver inflammation and fibrosis. In a small pilot study, Loomba et al. [70] showed that 48 weeks of metformin $(2.000 \mathrm{mg} /$ day $)$ did not have any significant effect on the histological features of NASH. In the following year, Haukeland et al. [71] developed a more significant study. The authors enrolled 48 patients with biopsy-proven NAFLD in a RCT with metformin or placebo for 6 months. The absence of histological changes as a result of the drug was confirmed, but a decline in the serum levels of both lipids and glucose was observed. Furthermore, in a RCT with metformin (500$1000 \mathrm{mg}$ daily for 12 months) versus placebo, Shields et al. [72] corroborated the absence of a significant positive effect on liver histology and also the lack of a significant weight loss. A systematic review of 8 RCTs showed no favourable effects of metformin on the histology of NASH although it can lead to weight loss [73]. Indeed, although metformin can be used in diabetic patients with NASH, no evidence exists to support its efficacy in terms of the histology of NASH [74] (see Table 4).

5.2. Ursodeoxycholic Acid. Ursodeoxycholic acid (UDCA) has been widely studied for the treatment of NASH for at least three reasons: its antiapoptotic properties and its capacity to decrease TNF- $\alpha$ and ER stress [75, 76]. Lindor et al. [77] performed a RCT of 166 patients with liver biopsy-proven
NASH who were treated with $13-15 \mathrm{mg} / \mathrm{kg}$ daily of UDCA or placebo for 24 months. The authors found no difference between the two arms in terms of histological improvement. Still, because good outcomes that resulted from the use of higher doses of UDCA were reported in liver disease [78], some authors tried to use a high dosage approach. Leuschner et al. [79] enrolled 185 patients with a histological diagnosis of NASH in a RCT and offered them high-dose UDCA (23-28 mg/kg daily) or placebo for 18 months. The authors reported a positive effect of the drug only on lobular inflammation but did not demonstrate any positive effects on fibrosis or on laboratory data. Ratziu et al. [80] developed a RCT that included 126 subjects with biopsy-proven NASH who were treated with $28-35 \mathrm{mg} / \mathrm{kg}$ daily or placebo for 12 months. The authors demonstrated that a high dose of UDCA was more effective in terms of a decrease in ALT and indirect indexes of fibrosis and IR, but the results were hampered by a lack of serial biopsies. This latter aspect makes the results of this study insufficient to justify the use of UDCA in patients with NASH. This assumption is clearly reported in the editorial by Haedrich and Dufour [81], who assumed that UDCA given in a monotherapy at the usual dose shows no positive effects in patients with NASH, and exerts only minor effects at a higher dose. Moreover, the potentially damaging adverse events that may occur during high-dose UDCA treatment should be noted and considered (see Table 5).

5.3. Statins. Hyperlipidaemia (hypertriglyceridaemia, hypercholesterolaemia, alone or together) is often associated with obesity and T2DM and is present in $20-80 \%$ of patients who are diagnosed with NASH $[82,83]$. In NASH, the plasma levels of lipids are increased and the accumulation of triacylglycerol in the liver is a hallmark of the pathogenesis of this disease [84]. In the same vein, it was reported that statins, which are inhibitors of hydroxymethylglutarylcoenzyme A reductase, might be a valid therapeutic option to decrease intrahepatic cholesterol and to improve the abnormal metabolism of lipids [85].

In a well-written review that was published last year, Eslami et al. [86] reported that only two studies concerned the 
TABLE 6

\begin{tabular}{|c|c|c|c|c|c|c|c|}
\hline \multirow{2}{*}{ Effects on } & \multirow{2}{*}{ Weight loss } & \multirow{2}{*}{ IR } & \multirow{2}{*}{ AST/ALT } & \multicolumn{2}{|c|}{ Histology } & \multirow{2}{*}{$\begin{array}{c}\text { Long-term } \\
\text { morbidity }\end{array}$} & \multirow{2}{*}{$\begin{array}{c}\text { Long-term } \\
\text { mortality }\end{array}$} \\
\hline & & & & Inflammation & Fibrosis & & \\
\hline Statins & No & No & No & No & No & Unproven & Unproven \\
\hline
\end{tabular}

TABLE 7

\begin{tabular}{lccccccc}
\hline Effects on & Weight loss & IR & AST/ALT & \multicolumn{2}{c}{$\begin{array}{c}\text { Histology } \\
\text { Inflammation }\end{array}$} & $\begin{array}{c}\text { Long-term } \\
\text { morbidity }\end{array}$ & $\begin{array}{c}\text { Long-term } \\
\text { mortality }\end{array}$ \\
\hline Pentoxifylline & No & No & Yes & No & No & Unproven & Unproven \\
\hline
\end{tabular}

use of statins in patients with NAFLD/NASH. These studies showed the prerequisites for a concrete evaluation although none of the available ones analysed the following relevant outcomes: liver-related morbidity, liver-related mortality, or all-cause mortality.

The first study was a trial that compared atorvastatin versus fenofibrate versus a combination of the two interventions [87]. In this study, no differences with regard to plasma liver enzyme activities or imaging findings were found, but when these two outcomes were evaluated together, atorvastatin appeared to be better than fenofibrate.

The other study was a small pilot trial that evaluated simvastatin versus placebo [88]. The authors reported no significant effects of simvastatin versus placebo in terms of the levels of AST and ALT and in terms of liver histology.

The known side effects of statins, such as myositis, myalgia, rhabdomyolysis, elevations in aminotransferases, and acute renal failure, are well described. However, the number of adverse events was not significantly different between groups in the two cited studies. Again, after a consideration of other works that have proposed the use of statins in the context of NASH, no adverse events were reported [89-91].

Indeed, statins, which seem to be safe in patients with $\mathrm{NASH}$, can be considered in particular situations such as in patients with NAFLD/NASH who have increased serum cholesterol levels. In this case, the increased cardiovascular risk can independently indicate the use of these drugs [92] (see Table 6).

5.4. Pentoxifylline. Pentoxifylline is a methylxanthine derivative and nonspecific phosphodiesterase inhibitor that is usually used in the treatment of intermittent claudication for its effects in the improvement of red blood cell flexibility, decrease in blood viscosity, and enhancement of aerobic glycolysis and oxygen consumption in ischaemic tissues [93]. Moreover, it was demonstrated that pentoxifylline decreases gene transcription of TNF- $\alpha$, which influences multiple steps of the cytokine/chemokine pathway [94]. Lee et al. [95] proposed a small RCT that did not involve a histological analysis; they compared pentoxifylline (1200 mg daily for 3 months) and placebo and showed that the only positive effect of the drug was on the AST level. In 2009, Rinella et al. [96] published a RCT in which patients with NASH were treated with pentoxifylline (1200 mg daily for 12 months) or placebo; the drug exerted a significant effect only on steatosis and cellular ballooning. A few years later, Zein et al. [97] developed a larger RCT that also included the histological analysis. Pentoxifylline (1200 mg daily for 12 months) improved steatosis and tissue inflammation compared with the placebo but did not show a significant influence on fibrosis. In the same year, van Wagner et al. [98] published a RCT with a similar structure as the previous trial and reported no significant positive action of the drug either on the biochemical data or on the liver histology. In 2011, a systematic review that concerned the use of pentoxifylline in patients with NASH [99] demonstrated that pentoxifylline seems to decrease both AST and ALT levels but cannot influence cytokine levels and histological aspects of NASH (see Table 7).

5.5. Orlistat. Orlistat is an enteric lipase inhibitor that was evaluated as a possible therapeutic choice for patients with NAFLD/NASH since it was reported that it might lead to weight reduction, decreased free fatty acid flux to the liver, and improved insulin sensitivity, without hepatotoxic adverse effects. This drug was studied in two RCTs in combination with lifestyle modification. Zelber-Sagi et al. [100] proposed a RCT in which patients were randomised to receive either orlistat (120 mg, 3 times daily for 6 months) or placebo; with this drug, patients showed an improvement in ALT levels, weight, and hepatic steatosis. However, these authors did not analyse the modifications in liver histology. In another RCT, Harrison et al. [101] randomised patients with biopsy-proven $\mathrm{NASH}$ to a $1400 \mathrm{kcal} /$ day diet and $800 \mathrm{IU}$ vitamin E/day with or without orlistat (the same dose with respect to the previous study but for 9 months) and demonstrated no significant improvement in AST/ALT levels, weight, insulin sensitivity, and liver histology. Notably, patients who lost 5\% or more of their weight also experienced a reduction in steatosis, IR, and plasma glucose, but only those subjects who lost $9 \%$ or more of their weight experienced an improvement in necroinflammation as well (see Table 8).

\section{Emerging Treatment Options}

6.1. Vitamin E Associations. After consideration of the articulated and multifactorial pathogenesis of NASH, it is reasonable to think that the combination of multiple drugs that are directed at different targets may lead to a gain in terms of effectiveness. The association of one molecule with one other drug with a certain degree of scientific evidence is reasonable. Indeed, vitamin E supplementation in combination with 
TABLE 8

\begin{tabular}{|c|c|c|c|c|c|c|c|}
\hline \multirow{2}{*}{ Effects on } & \multirow{2}{*}{ Weight loss } & \multirow{2}{*}{ IR } & \multirow{2}{*}{ AST/ALT } & \multicolumn{2}{|c|}{ Histology } & \multirow{2}{*}{$\begin{array}{l}\text { Long-term } \\
\text { morbidity }\end{array}$} & \multirow{2}{*}{$\begin{array}{l}\text { Long-term } \\
\text { mortality }\end{array}$} \\
\hline & & & & Inflammation & Fibrosis & & \\
\hline Orlistat & No & No & No & No & No & Unproven & Unproven \\
\hline
\end{tabular}

TABLE 9

\begin{tabular}{|c|c|c|c|c|c|c|c|}
\hline \multirow{2}{*}{ Effects on } & \multirow{2}{*}{ Weight loss } & \multirow{2}{*}{ IR } & \multirow{2}{*}{ AST/ALT } & \multicolumn{2}{|c|}{ Histology } & \multirow{2}{*}{$\begin{array}{c}\text { Long-term } \\
\text { morbidity }\end{array}$} & \multirow{2}{*}{$\begin{array}{l}\text { Long-term } \\
\text { mortality }\end{array}$} \\
\hline & & & & Inflammation & Fibrosis & & \\
\hline Vitamin E/UDCA & No & No & Yes & Unproven & Unproven & Unproven & Unproven \\
\hline
\end{tabular}

TABLE 10

\begin{tabular}{|c|c|c|c|c|c|c|c|}
\hline \multirow{2}{*}{ Effects on } & \multirow{2}{*}{ Weight loss } & \multirow{2}{*}{ IR } & \multirow{2}{*}{ AST/ALT } & \multicolumn{2}{|c|}{ Histology } & \multirow{2}{*}{$\begin{array}{c}\text { Long-term } \\
\text { morbidity }\end{array}$} & \multirow{2}{*}{$\begin{array}{c}\text { Long-term } \\
\text { mortality }\end{array}$} \\
\hline & & & & Inflammation & Fibrosis & & \\
\hline ARBS & Unproven & Yes & Unproven & Unproven & Unproven & Unproven & Unproven \\
\hline
\end{tabular}

other drugs has been widely used. In 2006, Dufour et al. [102] published a RCT in which patients with NASH were randomly allocated to receive UDCA $(12-15 \mathrm{mg} / \mathrm{kg}$ daily) with vitamin E (800 IU daily), UDCA with placebo, or placebo alone. The combination of UDCA and vitamin E led to better serum levels of alanine aminotransferase (ALT)/aspartate aminotransferase (AST) and liver steatosis in comparison with UDCA monotherapy. Notably, the authors did not exclude the possibility that, at a higher dosage, UDCA might be more effective, and the absence of an arm that included vitamin $\mathrm{E}$ plus placebo did not provide information about the efficacy of vitamin E monotherapy. The same study group [103] analysed the effects of UDCAvitamin $\mathrm{E}$ on adipokines and apoptosis of hepatocytes, which demonstrated that this combination improved the levels of transaminases as well as liver histology and decreased cellular apoptosis. Pietu et al. [104], through a large retrospective study, reported that the well-tolerated combination of UDCA and vitamin E significantly improved ALT, AST, and gammaglutamyl transpeptidase levels, although the authors did not evaluate the histological impact of this therapeutic approach. In this context, a RCT that compares vitamin E monotherapy with vitamin E plus UDCA might be useful.

It was reported that the association of vitamins $\mathrm{E}$ and $\mathrm{C}$ might reduce fibrosis in patients with NASH [105] as the combination of vitamin $\mathrm{E}$ with other antioxidants would lead to a regeneration of the oxidised form of the vitamin [106]. However, the lack of a RCT precludes the ability to accurately evaluate this therapeutic choice [107] (see Table 9).

6.2. Angiotensin II Receptor Blockers. The role of the reninangiotensin system (RAS) in renal and cardiovascular responses is well known. Angiotensin II receptor blockers (ARBs) are a consolidated family of antihypertensive drugs. However, other tissues produce RAS components that are regulated independently from RAS in the circulatory system. In the liver, chronic injury upregulates RAS in local tissues, which seems to contribute to the vicious cycle of steatosisnecroinflammation-fibrosis. Indeed, many authors suggest that ARBs may be useful in the treatment of NAFLD/NASH.
It was reported that losartan has an antifibrotic effect and improves steatosis and necroinflammation in patients affected by NASH [108, 109]. Interestingly, Torres et al. [110] proposed the use of losartan for NASH in a RCT (rosiglitazone versus rosiglitazone and metformin versus rosiglitazone and losartan) but found no significant results. On the contrary, the use of telmisartan shows the longest terminal elimination half time and the greatest affinity for the angiotensin II receptor type 1 among the ARBs. It was reported in animal models that this drug reduced weight, improved hyperinsulinaemia, and decreased triglycerides, steatosis, fibrosis, and liver macrophage infiltration [111-114]. Interestingly, Clemenz et al. [115] also indicated telmisartan as a partial PPAR-alpha agonist, which suggests that it causes a reduction of circulating and hepatic triglycerides. Georgescu et al. [116] first demonstrated that telmisartan (20 mg daily) was better than valsartan for the improvement of IR and liver histology (i.e., steatosis, lobular inflammation, ballooning, and fibrosis), and its action on IR was confirmed by Miura et al. [117]. With regard to its safety, Schumacher and Mancia [118] retrospectively analysed 50 studies on telmisartan and showed that it has a placebo-like tolerability. Indeed, among the ARBs, telmisartan is the most promising for the treatment of NASH in terms of both safety and efficacy on inflammation and fibrosis; however, the lack of a large RCT precludes the use of this drug as a consolidated option (see Table 10).

6.3. Pre- and Probiotics. It was demonstrated that bacterial overgrowth in the bowel is present in $50 \%$ of patients with NASH [119]. Moreover, a high-fat diet-induced obesity is related to changes in the composition of intestinal bacteria [120]. Indeed, modifications of the intestinal bacterial content might be involved in the pathogenesis of NASH through the enhancement of intestinal permeability, the direct activation of inflammatory cytokines, and the improvement of the absorption of endotoxins [121].

Aller et al. [122] proposed a double-blind RCT in which patients with metabolic liver disease were treated with 500 million Lactobacillus bulgaricus and Streptococcus thermophilus or placebo. Patients in the drug arm showed 
TABLE 11

\begin{tabular}{|c|c|c|c|c|c|c|c|}
\hline \multirow{2}{*}{ Effects on } & \multirow{2}{*}{ Weight loss } & \multirow{2}{*}{ IR } & \multirow{2}{*}{ AST/ALT } & \multicolumn{2}{|c|}{ Histology } & \multirow{2}{*}{$\begin{array}{l}\text { Long-term } \\
\text { morbidity }\end{array}$} & \multirow{2}{*}{$\begin{array}{l}\text { Long-term } \\
\text { mortality }\end{array}$} \\
\hline & & & & Inflammation & Fibrosis & & \\
\hline Pre- and probiotics & No & Yes & Yes & Unproven & Unproven & Unproven & Unproven \\
\hline
\end{tabular}

TABLE 12

\begin{tabular}{|c|c|c|c|c|c|c|c|}
\hline \multirow{2}{*}{ Effects on } & \multirow{2}{*}{ Weight loss } & \multirow{2}{*}{ IR } & \multirow{2}{*}{ AST/ALT } & \multicolumn{2}{|c|}{ Histology } & \multirow{2}{*}{$\begin{array}{c}\text { Long-term } \\
\text { morbidity }\end{array}$} & \multirow{2}{*}{$\begin{array}{c}\text { Long-term } \\
\text { mortality }\end{array}$} \\
\hline & & & & Inflammation & Fibrosis & & \\
\hline Fatty acid-bile & Unproven & Unproven & Unproven & Unproven & Unproven & Unproven & Unproven \\
\hline
\end{tabular}

an improvement in ALT/AST levels but did not show effects in terms of anthropometric parameters and cardiovascular risk factors. Malaguarnera et al. [123] evaluated the effects of Bifidobacterium longum, fructooligosaccharides, and lifestyle modification versus lifestyle modification alone, for the treatment of NASH. In this RCT, the authors showed that Bifidobacterium longum together with fructooligosaccharides significantly decreased TNF- $\alpha$, C-reactive protein, AST levels, IR, serum endotoxin levels, steatosis, and the "NASH activity index." Finally, Wong et al. [124] tested a Lepicol probiotic formula (Lactobacillus plantarum, Lactobacillus delbrueckii, Lactobacillus acidophilus, Lactobacillus rhamnosus, and Bifidobacterium bifidum) in a small trial to cure patients with biopsy-proven NASH. The authors obtained a reduction in liver fat, as measured by proton-magnetic resonance spectroscopy, and a decrease in AST levels.

In a meta-analysis published in 2013 [125], it was suggested that probiotics might significantly decrease the levels of ALT, AST, total cholesterol, TNF- $\alpha$, and IR and exert virtually positive effects on the pathogenesis of NASH (see Table 11).

6.4. Fatty Acid-Bile. Bile acids, but not UDCA, control metabolism by binding to the nuclear hormone receptor farnesoid $\mathrm{X}$ and to a transmembrane bile acid receptor. Stimulation of the farnesoid $\mathrm{X}$ receptor could increase insulin sensitivity and decrease both glucose and lipids. Transmembrane bile acid receptors are regulators of glucose homeostasis and lipid metabolism, and activation of these receptors stimulates energy expenditure and protects against obesity. Farnesoid X receptor agonists were proposed as possible treatment options for metabolic disorders such as T2DM, hypertriglyceridaemia, certain cases of cholestasis, and cholesterol gallstone disease [126]. Indeed, bile acids are metabolic integrators and are not solely regulators of bile-acid homeostasis. As a consequence, non-UDCA bile acids should also be considered in the context of NAFLD and NASH [127]. Similarly, Mudaliar et al. [128] developed a doubleblind, placebo-controlled, proof-of-concept study on the use of obeticholic acid in patients with NASH and T2DM. Six weeks of therapy with this drug led to an improvement in IR and a decrease in the indirect index of liver inflammation and fibrosis. More recently, Neuschwander-Tetri et al. [129] developed a multicentre, double-blind, placebo-controlled trial, enrolling patients affected by NASH. Authors proposed a 72 -week treatment with obeticholic acid (25 mg daily, orally). Patients in the drug arm with respect to those in the placebo one showed an improvement in the main histological features of NASH. However, as the same authors reported, data about the long-term benefit and safety of this drug are today not available (see Table 12).

6.5. Omega-3. It was reported that natural fatty acids such as long-chain omega-3 (LCn-3) polyunsaturated fatty acids (PUFAs), including eicosapentaenoic acid and docosahexaenoic acid, show bioactive properties; therefore, these are a potential treatment option for patients with NASH [130]. LCn-3 PUFA supplementation is a promising treatment for patients with NAFLD/NASH as it can affect different aspects of this complex disease. Animal studies and preliminary clinical trials have demonstrated that purified n-3 supplementation or fish intake might prevent or reverse the rate of NASH [131]. Notably, the therapeutic effects of LCn-3 PUFAs were verified in three studies, two of which included patients with NAFLD $[132,133]$ and one of which evaluated subjects with NASH [134]. In the latter study, 1 year of treatment with eicosapentaenoic acid significantly improved steatosis (imaging and histological) as well as the levels of AST/ALT, cholesterol, iron, and free fatty acids but did not have any effect on IR. Markedly, the lack of a control group and the small sample size do not allow for significant conclusions (see Table 13).

6.6. L-Carnitine. L-Carnitine is a modulator of mitochondrial free fatty acid transport and oxidation that has demonstrated a significant effect on oxidative stress, activation of immune cells, and the integrity of the epithelial barrier. Interestingly, a potential therapeutic value was reported for the use of L-carnitine supplementation in cases of intestinal inflammation [135]. On the assumption that liver steatosis is a common pattern of both hepatitis $\mathrm{C}$ and NAFLD/NASH, a total of 70 affected patients were randomly assigned to receive interferon and ribavirin alone or plus carnitine; the patients in this second arm showed a relevant decrease in steatosis [136].

In a high quality RCT conducted by Malaguarnera et al. [137], patients with $\mathrm{NASH}$ and control subjects were randomly treated with L-carnitine plus modified diet or modified diet alone. L-Carnitine plus lifestyle intervention for 6 months improved steatosis, the "NASH activity score," AST/ALT levels, IR, plasma glucose, and total and lowdensity lipoprotein cholesterol. 
TABLE 13

\begin{tabular}{|c|c|c|c|c|c|c|c|}
\hline \multirow{2}{*}{ Effects on } & \multirow{2}{*}{ Weight loss } & \multirow{2}{*}{ IR } & \multirow{2}{*}{ AST/ALT } & \multicolumn{2}{|c|}{ Histology } & \multirow{2}{*}{$\begin{array}{l}\text { Long-term } \\
\text { morbidity }\end{array}$} & \multirow{2}{*}{$\begin{array}{c}\text { Long-term } \\
\text { mortality }\end{array}$} \\
\hline & & & & Inflammation & Fibrosis & & \\
\hline Omega-3 & Unproven & Unproven & Unproven & Unproven & Unproven & Unproven & Unproven \\
\hline
\end{tabular}

TABLE 14

\begin{tabular}{|c|c|c|c|c|c|c|c|}
\hline \multirow{2}{*}{ Effects on } & \multirow{2}{*}{ Weight loss } & \multirow{2}{*}{ IR } & \multirow{2}{*}{ AST/ALT } & \multicolumn{2}{|c|}{ Histology } & \multirow{2}{*}{$\begin{array}{c}\text { Long-term } \\
\text { morbidity }\end{array}$} & \multirow{2}{*}{$\begin{array}{c}\text { Long-term } \\
\text { mortality }\end{array}$} \\
\hline & & & & Inflammation & Fibrosis & & \\
\hline L-Carnitine & Unproven & Unproven & Unproven & Unproven & Unproven & Unproven & Unproven \\
\hline
\end{tabular}

The results of this supplementation therapy are very interesting and need to be confirmed in a large and wellstructured RCT that tests the efficacy of L-carnitine used alone or with other drugs (see Table 14).

\section{Conclusions and Future Perspectives}

NASH will continue to be the most common liver-related health problem in the future. In fact, the emerging direct antiviral therapies for hepatitis $\mathrm{C}$ and the well-consolidated drugs for hepatitis B will allow these liver diseases to be treatable in a vast majority of cases. On the contrary, the best treatment modalities for fatty liver disease together with alcoholrelated disease have yet to be elucidated. Today, the incidence of NAFLD and NASH is increasing in industrialised and emerging countries, and this increase is strictly connected to the increase in obesity, visceral obesity, T2DM, IR, and arterial hypertension. In the pathogenesis of NASH, according to the most recent view, many events occur in parallel, and all are potential therapeutic targets. The principally studied actors are the following: IR, oxidative stress, gut, adipose and pancreas tissues, altered lipid metabolism, bile acids, gut microbiota, systemic chronic inflammation, and genetic patterns.

Today, the standard of care for the treatment of NASH is lifestyle modification. However, its effect on liver histology in patients with NASH warrants further evaluation, as the lack of evidence regarding the optimal dietary nutrient composition and exercise is a significant ongoing problem. Moreover, a vast majority of patients show a lack of compliance with diet and exercise programs due to their attitudes or physical inability. Currently, the first-line pharmacological approaches for NASH are vitamin $\mathrm{E}$ and pioglitazone as they are unique drugs that have provided a sufficient degree of evidence in terms of efficacy. In particular, both vitamin $\mathrm{E}$ and pioglitazone improve the levels of transaminases, fat accumulation, and liver inflammation. However, these two drugs also display evident limits. In particular, vitamin $\mathrm{E}$ has not been proven to have an effect on fibrosis or on the longterm morbidity and mortality, and its possible use is limited to patients without T2DM. With regard to pioglitazone, its main restriction is its negative impact on weight. In addition, the safety of this drug remains uncertain as data about the long-term use of vitamin E or pioglitazone are not available. On the one hand, many drugs have been tested through RCTs, which showed only a few relevant results in terms of efficacy, such as metformin, UDCA, statins, pentoxifylline, and orlistat. On the other hand, many emerging treatment options can be found in the literature. Among them, in our opinion, the most attention should be focused on telmisartan, a safe antihypertensive drug. This drug, although it has not yet been tested in a large and well-structured RCT, seems to have a significant impact on IR, liver steatosis, inflammation, and liver fibrosis according to preliminary studies. Additionally L-carnitine is a particularly promising supplement that could be evaluated alone or in association with other drugs.

In the complex establishment of a study on NASH, some aspects should be improved with respect to the available papers. Lifestyle intervention should be clearly defined as it needs to represent a clear point of comparison with respect to newly proposed drugs. In addition, we suggest that the lifestyle intervention itself has a significant potential to expand as specific and widely accepted alimentary, exercise, and counselling indications do not actually exist. Future RCTs need to include histological endpoints and an adequate duration and should also consider patients with advanced fibrosis. Notably, an adequate follow-up period will allow for the assessment of the long-term efficacy and safety of the proposed treatments and for the evaluation of strong outcomes such as the development of cirrhosis and hepatocellular carcinoma, the morbidity and liver, cardiovascular, and all-cause mortality.

Today, many authors continue to develop RCTs with different agents in order to cure patients with NASH and NASHrelated fibrosis [138]. However, because multiple parallel roads characterise the complex pathogenesis of $\mathrm{NASH}$, we suggest the evaluation of the combination of different drugs that could act synergistically on the onset and progression of this disease. According to this view, the development of individualised treatment would be opportune. Consequently, the experimental use of vitamin E and UDCA without obvious positive results was a good course of action.

In conclusion, many aspects with regard to therapy for patients with NASH should be implemented. In particular, lifestyle interventions should be clearly defined and optimised, the individualisation of a pharmacological approach with associations of different drugs might be tested, and large RCTs with histological outcomes and long-term observations should be developed.

\section{Conflict of Interests}

The authors declare that there is no conflict of interests regarding the publication of this paper. 


\section{References}

[1] N. Chalasani, Z. Younossi, J. E. Lavine et al., "The diagnosis and management of non-alcoholic fatty liver disease: practice guideline by the American Association for the study of liver diseases, American college of gastroenterology, and the American gastroenterological association," Hepatology, vol. 55, no. 6, pp. 2005-2023, 2012.

[2] M. Krawczyk, L. Bonfrate, and P. Portincasa, "Nonalcoholic fatty liver disease," Best Practice and Research: Clinical Gastroenterology, vol. 24, no. 5, pp. 695-708, 2010.

[3] K. Law and E. M. Brunt, "Nonalcoholic fatty liver disease," Clinics in Liver Disease, vol. 14, no. 4, pp. 591-604, 2010.

[4] Z. M. Younossi, M. Stepanova, M. Afendy et al., "Changes in the prevalence of the most common causes of chronic liver diseases in the United States from 1988 to 2008," Clinical Gastroenterology and Hepatology, vol. 9, no. 6, pp. 524-530, 2011.

[5] M. Blachier, H. Leleu, M. Peck-Radosavljevic, D.-C. Valla, and F. Roudot-Thoraval, "The burden of liver disease in Europe: a review of available epidemiological data. European Association for the Study of the Liver 2013," Journal of Hepatology, vol. 58, no. 3, pp. 593-608, 2013.

[6] C. K. Argo, P. G. Northup, A. M. S. Al-Osaimi, and S. H. Caldwell, "Systematic review of risk factors for fibrosis progression in non-alcoholic steatohepatitis," Journal of Hepatology, vol. 51, no. 2, pp. 371-379, 2009.

[7] P. Angulo, "Non alcoholic fatty liver disease," The New England Journal of Medicine, vol. 346, no. 4, pp. 2121-1231, 2002.

[8] OECD Health Data 2012; Eurostat Statistics Database, WHO Global Infobase, 2014.

[9] M. Soresi, L. Giannitrapani, A. M. Florena et al., "Reliability of the bright liver echo pattern in diagnosing steatosis in patients with cryptogenic and HCV-related hypertransaminasaemia," Clinical Radiology, vol. 64, no. 12, pp. 1181-1187, 2009.

[10] O. T. Ayonrinde, J. K. Olynyk, L. J. Beilin et al., "Gender-specific differences in adipose distribution and adipocytokines influence adolescent nonalcoholic fatty liver disease," Hepatology, vol. 53, no. 3, pp. 800-809, 2011.

[11] E. M. Koehler, J. N. L. Schouten, B. E. Hansen et al., "Prevalence and risk factors of non-alcoholic fatty liver disease in the elderly: results from the Rotterdam study," Journal of Hepatology, vol. 57, no. 6, pp. 1305-1311, 2012.

[12] G. Vernon, A. Baranova, and Z. M. Younossi, "Systematic review: the epidemiology and natural history of non-alcoholic fatty liver disease and non-alcoholic steatohepatitis in adults," Alimentary Pharmacology and Therapeutics, vol. 34, no. 3, pp. 274-285, 2011.

[13] G. Marchesini, E. Bugianesi, G. Forlani et al., "Nonalcoholic fatty liver, steatohepatitis, and the metabolic syndrome," Hepatology, vol. 37, no. 4, pp. 917-923, 2003.

[14] C.-J. Liu, "Prevalence and risk factors for non-alcoholic fatty liver disease in Asian people who are not obese," Journal of Gastroenterology and Hepatology, vol. 27, no. 10, pp. 1555-1560, 2012.

[15] S. H. Caldwell, Y. Ikura, J. C. Iezzoni, and Z. Liu, "Has natural selection in human populations produced two types of metabolic syndrome (with and without fatty liver)?" Journal of Gastroenterology and Hepatology, vol. 22, no. 1, pp. S11-S19, 2007.

[16] C. P. Day and O. F. W. James, "Steatohepatitis: a tale of two 'Hits'?” Gastroenterology, vol. 114, no. 4 I, pp. 842-845, 1998.

[17] G. Musso, R. Gambino, M. Cassader, and G. Pagano, "Metaanalysis: Natural history of non-alcoholic fatty liver disease
(NAFLD) and diagnostic accuracy of non-invasive tests for liver disease severity," Annals of Medicine, vol. 43, no. 8, pp. 617-649, 2011.

[18] L. A. Adams, J. F. Lymp, J. Sauver et al., "The natural history of nonalcoholic fatty liver disease: a population-based cohort study," Gastroenterology, vol. 129, no. 1, pp. 113-121, 2005.

[19] H. Tilg and A. R. Moschen, "Evolution of inflammation in nonalcoholic fatty liver disease: the multiple parallel hits hypothesis," Hepatology, vol. 52, no. 5, pp. 1836-1846, 2010.

[20] F. Kim, M. Pham, E. Maloney et al., "Vascular inflammation, insulin resistance, and reduced nitric oxide production precede the onset of peripheral insulin resistance," Arteriosclerosis, Thrombosis, and Vascular Biology, vol. 28, no. 11, pp. 1982-1988, 2008.

[21] J. P. Warne, "Tumour necrosis factor $\alpha$ : a key regulator of adipose tissue mass," Journal of Endocrinology, vol. 177, no. 3, pp. 351-355, 2003.

[22] N. E. Sunny, E. J. Parks, J. D. Browning, and S. C. Burgess, "Excessive hepatic mitochondrial TCA cycle and gluconeogenesis in humans with nonalcoholic fatty liver disease," Cell Metabolism, vol. 14, no. 6, pp. 804-810, 2011.

[23] S. Satapati, N. E. Sunny, B. Kucejova et al., "Elevated TCA cycle function in the pathology of diet-induced hepatic insulin resistance and fatty liver," Journal of Lipid Research, vol. 53, no. 6, pp. 1080-1092, 2012.

[24] M. Asrih and F. R. Jornayvaz, "Inflammation as a potential link between nonalcoholic fatty liver disease and insulin resistance," Journal of Endocrinology, vol. 218, no. 3, pp. R25-R36, 2013.

[25] G. J. J. Holst and J. Gromada, "Role of incretin hormones in the regulation of insulin secretion in diabetic and nondiabetic humans," American Journal of Physiology-Endocrinology and Metabolism, vol. 287, no. 2, pp. E199-E206, 2004.

[26] B. Staels and V. A. Fonseca, "Bile acids and metabolic regulation: mechanisms and clinical responses to bile acid sequestration," Diabetes care, vol. 32, supplement 2, pp. S237-S245, 2009.

[27] F. K. Knop, "Bile-induced secretion of glucagon-like peptide-1: Pathophysiological implications in type 2 diabetes?" The American Journal of Physiology-Endocrinology and Metabolism, vol. 299, no. 1, pp. E10-E13, 2010.

[28] K. Wouters, M. V. Bilsen, P. J. V. Gorp et al., "Intrahepatic cholesterol influences progression, inhibition and reversal of non-alcoholic steatohepatitis in hyperlipidemic mice," FEBS Letters, vol. 584, no. 5, pp. 1001-1005, 2010.

[29] L. Zhao, Y. Chen, R. Tang et al., "Inflammatory stress exacerbates hepatic cholesterol accumulation via increasing cholesterol uptake and de novo synthesis," Journal of Gastroenterology and Hepatology, vol. 26, no. 5, pp. 875-883, 2011.

[30] N. J.-F. Tanti and J. Jager, "Cellular mechanisms of insulin resistance: role of stress-regulated serine kinases and insulin receptor substrates (IRS) serine phosphorylation," Current Opinion in Pharmacology, vol. 9, no. 6, pp. 753-762, 2009.

[31] L. Li, M. A. Hossain, S. Sadat et al., "Lecithin cholesterol acyltransferase null mice are protected from diet-induced obesity and insulin resistance in a gender-specific manner through multiple pathways," The Journal of Biological Chemistry, vol. 286, no. 20, pp. 17809-17820, 2011.

[32] L. P. Hager, L. Li, H. Pun et al., "Lecithin:cholesterol acyltransferase deficiency protects against cholesterol-induced hepatic endoplasmic reticulum stress in mice," The Journal of Biological Chemistry, vol. 287, no. 24, pp. 20755-20768, 2012. 
[33] A. Vrieze, E. van Nood, F. Holleman et al., "Transfer of intestinal microbiota from lean donors increases insulin sensitivity in individuals with metabolic syndrome," Gastroenterology, vol. 143, no. 4, pp. 913.e7-916.e7, 2012.

[34] L.-F. Zhao, J.-M. Jia, and D.-W. Han, “The role of enterogenous endotoxemia in the pathogenesis of non-alcoholic steatohepatitis," Zhonghua Gan Zang Bing Za Zhi, vol. 12, no. 10, p. 632, 2004.

[35] K. Imajo, K. Fujita, M. Yoneda et al., "Hyperresponsivity to low-dose endotoxin during progression to nonalcoholic steatohepatitis is regulated by leptin-mediated signaling," Cell Metabolism, vol. 16, no. 1, pp. 44-54, 2012.

[36] S. Zelber-Sagi, D. Nitzan-Kaluski, R. Goldsmith et al., "Long term nutritional intake and the risk for non-alcoholic fatty liver disease (NAFLD): a population based study," Journal of Hepatology, vol. 47, no. 5, pp. 711-717, 2007.

[37] S. Zelber-Sagi, D. Nitzan-Kaluski, R. Goldsmith et al., "Role of leisure-time physical activity in nonalcoholic fatty liver disease: a population-based study," Hepatology, vol. 48, no. 6, pp. 17911798, 2008.

[38] V. Ratziua, S. Bellentanib, H. Cortez-Pintoc et al., "A position statement on NAFLD/NASH based on the EASL 2009 special conference," Journal of Hepatology, vol. 53, no. 2, pp. 372-384, 2010.

[39] G. C. Farrell, S. Chitturi, G. K. K. Lau, and J. D. Sollano, "Guidelines for the assessment and management of non-alcoholic fatty liver disease in the Asia-Pacific region: executive summary," Journal of Gastroenterology and Hepatology, vol. 22, no. 6, pp. 775-777, 2007.

[40] P. Loria, L. E. Adinolfi, S. Bellentani et al., "Practice guidelines for the diagnosis and management of nonalcoholic fatty liver disease: a decalogue from the Italian Association for the Study of the Liver (AISF) expert committee," Digestive and Liver Disease, vol. 42, no. 4, pp. 272-282, 2010.

[41] N. Chalasani, Z. Younossi, J. E. Lavine et al., "The diagnosis and management of non-alcoholic fatty liver disease: practice Guideline by the American Association for the Study of Liver Diseases, American College of Gastroenterology, and the American Gastroenterological Association," Hepatology, vol. 55, no. 6, pp. 2005-2023, 2012.

[42] E. Centis, S. Moscatiello, E. Bugianesi et al., "Stage of change and motivation to healthier lifestyle in non-alcoholic fatty liver disease," Journal of Hepatology, vol. 58, no. 4, pp. 771-777, 2013.

[43] S. Zelber-Sagi, R. Lotan, A. Shlomai et al., "Predictors for incidence and remission of NAFLD in the general population during a seven-year prospective follow-up," Journal of Hepatology, vol. 56, no. 5, pp. 1145-1151, 2012.

[44] K. Promrat, D. E. Kleiner, H. M. Niemeier et al., "Randomized controlled trial testing the effects of weight loss on nonalcoholic steatohepatitis," Hepatology, vol. 51, no. 1, pp. 121-129, 2010.

[45] The Diabetes Prevention Program Research Group, “The diabetes prevention program (DPP): description of lifestyle intervention," Diabetes Care, vol. 25, no. 12, pp. 2165-2171, 2002.

[46] G. Musso, R. Gambino, M. Cassader, and G. Pagano, "A metaanalysis of randomized trials for the treatment of nonalcoholic fatty liver disease," Hepatology, vol. 52, no. 1, pp. 79-104, 2010.

[47] F. H. Luyckx, C. Desaive, A. Thiry et al., "Liver abnormalities in severely obese subjects: effect of drastic weight loss after gastroplasty," International Journal of Obesity and Related Metabolic Disorders, vol. 22, no. 3, pp. 222-226, 1998.

[48] C. Eckard, R. Cole, J. Lockwood et al., "Prospective histopathologic evaluation of lifestyle modification in nonalcoholic fatty liver disease: a randomized trial," Therapeutic Advances in Gastroenterology, vol. 6, no. 4, pp. 249-259, 2013.

[49] A. George, A. Bauman, A. Johnston et al., "Independent effects of physical activity in patients with nonalcoholic fatty liver disease," Hepatology, vol. 50, no. 1, pp. 68-76, 2009.

[50] K. Hallsworth, G. Fattakhova, K. G. Hollingsworth et al., "Resistance exercise reduces liver fat and its mediators in nonalcoholic fatty liver disease independent of weight loss," Gut, vol. 60, no. 9, pp. 1278-1283, 2011.

[51] K. Kantartzis, C. Thamer, A. Peter et al., "High cardiorespiratory fitness is an independent predictor of the reduction in liver fat during a lifestyle intervention in non-alcoholic fatty liver disease," Gut, vol. 58, no. 9, pp. 1281-1288, 2009.

[52] G. Targher, F. Marra, and G. Marchesini, "Increased risk of cardiovascular disease in non-alcoholic fatty liver disease: causal effect or epiphenomenon?" Diabetologia, vol. 51, no. 11, pp. 1947-1953, 2008.

[53] L. Peng, J. Wang, and F. Li, "Weight reduction for non-alcoholic fatty liver disease," Cochrane Database of Systematic Reviews, vol. 15, no. 6, Article ID CD003619, 2011.

[54] C. Thoma, C. P. Day, and M. I. Trenell, "Lifestyle interventions for the treatment of non-alcoholic fatty liver disease in adults: a systematic review," Journal of Hepatology, vol. 56, no. 1, pp. 255266, 2012.

[55] M. Kugelmas, D. B. Hill, B. Vivian et al., "Cytokines and NASH: a pilot study of the effects of lifestyle modification and vitamin E," Hepatology, vol. 38, no. 2, pp. 413-419, 2003.

[56] A. J. Sanyal, N. Chalasani, K. V. Kowdley et al., "Pioglitazone, vitamin E, or placebo for nonalcoholic steatohepatitis," The New England Journal of Medicine, vol. 362, no. 18, pp. 1675-1685, 2010.

[57] G. ErsöZ, F. Günşar, Z. Karasu et al., "Management of fatty liver disease with vitamin $\mathrm{E}$ and $\mathrm{C}$ compared to ursodeoxycholic acid treatment," Turkish Journal of Gastroenterology, vol. 16, no. 3, pp. 124-128, 2005.

[58] H.-F. Ji, Y. Sun, and L. Shen, "Effect of vitamin E supplementation on aminotransferase levels in patients with NAFLD, NASH, and CHC: results from a meta-analysis," Nutrition, vol. 30, no. 9, pp. 986-991, 2014.

[59] T. Pacana and A. J. Sanyal, "Vitamin E and nonalcoholic fatty liver disease," Current Opinion in Clinical Nutrition and Metabolic Care, vol. 15, no. 6, pp. 641-648, 2012.

[60] E. R. Miller III, R. Pastor-Barriuso, D. Dalal et al., "Metaanalysis: high-dosage vitamin E supplementation may increase all-cause mortality," Annals of Internal Medicine, vol. 142, pp. 3746, 2005.

[61] K. Promrat, G. Lutchman, G. I. Uwaifo et al., "A pilot study of pioglitazone treatment for nonalcoholic steatohepatitis," Hepatology, vol. 39, no. 1, pp. 188-196, 2004.

[62] G. Lutchman, A. Modi, D. E. Kleiner et al., "The effects of discontinuing pioglitazone in patients with nonalcoholic steatohepatitis," Hepatology, vol. 46, no. 2, pp. 424-429, 2007.

[63] R. Belfort, S. A. Harrison, K. Brown et al., "A placebo-controlled trial of pioglitazone in subjects with nonalcoholic steatohepatitis," The New England Journal of Medicine, vol. 355, no. 22, pp. 2297-2307, 2006.

[64] G. P. Aithal, J. A. Thomas, P. V. Kaye et al., "Randomized, placebo-controlled trial of pioglitazone in nondiabetic subjects with nonalcoholic steatohepatitis," Gastroenterology, vol. 135, no. 4, pp. 1176-1184, 2008. 
[65] G. Musso, M. Cassader, F. Rosina, and R. Gambino, "Impact of current treatments on liver disease, glucose metabolism and cardiovascular risk in non-alcoholic fatty liver disease (NAFLD): a systematic review and meta-analysis of randomised trials," Diabetologia, vol. 55, no. 4, pp. 885-904, 2012.

[66] V. Ratziu, P. Giral, S. Jacqueminet et al., "Rosiglitazone for nonalcoholic steatohepatitis: one-year results of the randomized placebo-controlled Fatty Liver Improvement with Rosiglitazone Therapy (FLIRT) Trial," Gastroenterology, vol. 135, no. 1, pp. 100110, 2008.

[67] E. Boettcher, G. Csako, F. Pucino et al., "Meta-analysis: pioglitazone improves liver histology and fibrosis in patients with non-alcoholic steatohepatitis," Alimentary Pharmacology and Therapeutics, vol. 35, no. 1, pp. 66-75, 2012.

[68] J. P. Arab, R. Candia, R. Zapata et al., "Management of nonalcoholic fatty liver disease: an evidence-based clinical practice review," World Journal of Gastroenterology, vol. 14, no. 34, pp. 12182-12201, 2014.

[69] S. Nair, A. M. Diehl, M. Wiseman et al., "Metformin in the treatment of non-alcoholic steatohepatitis: a pilot open label trial," Alimentary Pharmacology and Therapeutics, vol. 20, no. 1, pp. 23-28, 2004.

[70] R. Loomba, G. Lutchman, D. E. Kleiner et al., "Clinical trial: Pilot Study of metformin for the treatment of non-alcoholic steatohepatitis," Alimentary Pharmacology and Therapeutics, vol. 29, no. 2, pp. 172-182, 2009.

[71] J. W. Haukeland, Z. Konopski, H. B. Eggesbø et al., "Metformin in patients with non-alcoholic fatty liver disease: a randomized, controlled trial," Scandinavian Journal of Gastroenterology, vol. 44, no. 7, pp. 853-860, 2009.

[72] W. W. Shields, K. E. Thompson, G. A. Grice et al., "The effect of metformin and standard therapy versus standard therapy alone in nondiabetic patients with insulin resistance and nonalcoholic steatohepatitis (NASH): a pilot trial," Therapeutic Advances in Gastroenterology, vol. 2, no. 3, pp. 157-163, 2009.

[73] D. Shyangdan, C. Clar, N. Ghouri et al., "Insulin sensitisers in the treatment of non-alcoholic fatty liver disease: a systematic review," Health Technology Assessment, vol. 15, no. 38, pp. 1-110, 2011.

[74] Z. M. Younossi, M. J. Reyes, A. Mishra et al., "Systematic review with meta-analysis: non-alcoholic steatohepatitis-a case for personalised treatment based on pathogenic targets," Alimentary Pharmacology and Therapeutics, vol. 39, no. 1, pp. 314, 2014.

[75] U. Özcan, E. Yilmaz, L. Özcan et al., "Chemical chaperones reduce ER stress and restore glucose homeostasis in a mouse model of type 2 diabetes," Science, vol. 313, no. 5790, pp. 11371140, 2006.

[76] J. D. Amaral, R. J. S. Viana, R. M. Ramalho et al., "Bile acids: regulation of apoptosis by ursodeoxycholic acid," Journal of Lipid Research, vol. 50, no. 9, pp. 1721-1734, 2009.

[77] K. D. Lindor, K. V. Kowdley, E. J. Heathcote et al., "Ursodeoxycholic acid for treatment of nonalcoholic steatohepatitis: results of a randomized trial," Hepatology, vol. 39, no. 3, pp. 770-778, 2004.

[78] S. A. Mitchell, D. S. Bansi, N. Hunt et al., "A preliminary trial of high-dose ursodeoxycholic acid in primary sclerosing cholangitis," Gastroenterology, vol. 121, no. 4, pp. 900-907, 2001.

[79] U. F. H. Leuschner, B. Lindenthal, G. Herrmann et al., "Highdose ursodeoxycholic acid therapy for nonalcoholic steatohepatitis: a double-blind, randomized, placebo-controlled trial," Hepatology, vol. 52, no. 2, pp. 472-479, 2010.
[80] V. Ratziu, V. De Ledinghen, F. Oberti et al., "A randomized controlled trial of high-dose ursodesoxycholic acid for nonalcoholic steatohepatitis," Journal of Hepatology, vol. 54, no. 5, pp. 1011-1019, 2011.

[81] M. Haedrich and J.-F. Dufour, "UDCA for NASH: end of the story?” Journal of Hepatology, vol. 54, no. 5, pp. 856-858, 2011.

[82] E. E. Powell, W. G. E. Cooksley, R. Hanson et al., "The natural history of nonalcoholic steatohepatitis: a follow-up study of forty-two patients for up to 21 years," Hepatology, vol. 11, no. 1, pp. 74-80, 1990.

[83] B. R. Bacon, M. J. Farahvash, C. G. Janney et al., "Nonalcoholic steatohepatitis: an expanded clinical entity," Gastroenterology, vol. 107, no. 4, pp. 1103-1109, 1994.

[84] P. Puri, R. A. Baillie, M. M. Wiest et al., "A lipidomic analysis of nonalcoholic fatty liver disease," Hepatology, vol. 46, no. 4, pp. 1081-1090, 2007.

[85] M. H. Ahmed, "Rosuvastatin: a safe and effective treatment for dyslipidaemia associated with non-alcoholic steatohepatitis (NASH)," Scandinavian Journal of Gastroenterology, vol. 41, no. 5, p. 631, 2006.

[86] L. Eslami, S. Merat, R. Malekzadeh et al., "Statins for nonalcoholic fatty liver disease and non-alcoholic steatohepatitis," The Cochrane Database of Systematic Reviews, vol. 27, no. 12, Article ID CD008623, 2013.

[87] V. G. Athyros, D. P. Mikhailidis, T. P. Didangelos et al., "Effect of multifactorial treatment on non-alcoholic fatty liver disease in metabolic syndrome: a randomised study," Current Medical Research and Opinion, vol. 22, no. 5, pp. 873-883, 2006.

[88] A. Nelson, D. M. Torres, A. E. Morgan et al., "A pilot study using simvastatin in the treatment of nonalcoholic steatohepatitis: a randomized placebo-controlled trial," Journal of Clinical Gastroenterology, vol. 43, no. 10, pp. 990-994, 2009.

[89] E. Gómez-Domínguez, J. P. Gisbert, J. A. Moreno-Monteagudo et al., "A pilot study of atorvastatin treatment in dyslipemid, non-alcoholic fatty liver patients," Alimentary Pharmacology and Therapeutics, vol. 23, no. 11, pp. 1643-1647, 2006.

[90] J. H. Lewis, M. E. Mortensen, S. Zweig et al., "Efficacy and safety of high-dose pravastatin in hypercholesterolemic patients with well-compensated chronic liver disease: results of a prospective, randomized, double-blind, placebo-controlled, multicenter trial," Hepatology, vol. 46, no. 5, pp. 1453-1463, 2007.

[91] H. Tavakkoli, H. Adilipour, Z. Ghaemaghami et al., "Simvastatin in treatment of non-alcoholic steatohepatitis: a clinical trial," Govaresh, vol. 14, p. 28, 2009.

[92] F. Taylor, M. D. Huffman, A. F. Macedo et al., "Statins for the primary prevention of cardiovascular disease," Cochrane Database of Systematic Reviews, vol. 31, no. 1, Article ID CD004816, 2013.

[93] G. Hepgül, S. TanrIkulu, H. R. Ünalp et al., "Preventive effect of pentoxifylline on acute radiation damage via antioxidant and anti-inflammatory pathways," Digestive Diseases and Sciences, vol. 55, no. 3, pp. 617-625, 2010.

[94] D. G. Duman, F. Ozdemir, E. Birben et al., "Effects of pentoxifylline on TNF-alpha production by peripheral blood mononuclear cells in patients with nonalcoholic steatohepatitis," Digestive Diseases and Sciences, vol. 52, no. 10, pp. 2520-2524, 2007.

[95] Y.-M. Lee, D. S. Sutedja, C.-T. Wai et al., "A randomized controlled pilot study of Pentoxifylline in patients with nonalcoholic steatohepatitis (NASH)," Hepatology International, vol. 2, no. 2, pp. 196-201, 2008. 
[96] M. E. Rinella, S. Koppe, E. M. Brunt et al., “563 pentoxifylline improves ALT and histology in patients with NASH, a double blind placebo controlled trial," Gastroenterology, vol. 136, no. 5, supplement 1, pp. A-88-A-89, 2009.

[97] C. O. Zein, L. M. Yerian, P. Gogate et al., "Pentoxifylline improves nonalcoholic steatohepatitis: a randomized placebocontrolled trial," Hepatology, vol. 54, no. 5, pp. 1610-1619, 2011.

[98] L. B. van Wagner, S. W. P. Koppe, E. M. Brunt et al., "Pentoxifylline for the treatment of non-alcoholic steatohepatitis: a randomized controlled trial," Annals of Hepatology, vol. 10, no. 3, pp. 277-286, 2011.

[99] W. Li, L. Zheng, C. Sheng et al., "Systematic review on the treatment of pentoxifylline in patients with non-alcoholic fatty liver disease," Lipids in Health and Disease, vol. 10, article 49, 2011.

[100] S. Zelber-Sagi, A. Kessler, E. Brazowsky et al., "A double-blind randomized placebo-controlled trial of orlistat for the treatment of nonalcoholic fatty liver disease," Clinical Gastroenterology and Hepatology, vol. 4, no. 5, pp. 639-644, 2006.

[101] S. A. Harrison, W. Fecht, E. M. Brunt, and B. A. NeuschwanderTetri, "Orlistat for overweight subjects with nonalcoholic steatohepatitis: a randomized, prospective trial," Hepatology, vol. 49, no. 1, pp. 80-86, 2009.

[102] J.-F. Dufour, C. M. Oneta, J.-J. Gonvers et al., "Randomized placebo-controlled trial of ursodeoxycholic acid with vitamin E in nonalcoholic steatohepatitis," Clinical Gastroenterology and Hepatology, vol. 4, no. 12, pp. 1537-1543, 2006.

[103] M. L. Balmer, K. Siegrist, A. Zimmermann, and J.-F. Dufour, "Effects of ursodeoxycholic acid in combination with vitamin $\mathrm{E}$ on adipokines and apoptosis in patients with nonalcoholic steatohepatitis," Liver International, vol. 29, no. 8, pp. 1184-1188, 2009.

[104] F. Pietu, O. Guillaud, T. Walter et al., "Ursodeoxycholic acid with vitamin $\mathrm{E}$ in patients with nonalcoholic steatohepatitis: long-term results," Clinics and Research in Hepatology and Gastroenterology, vol. 36, no. 2, pp. 146-155, 2012.

[105] S. A. Harrison, S. Torgerson, P. Hayashi et al., "Vitamin E and vitamin $\mathrm{C}$ treatment improves fibrosis in patients with nonalcoholic steatohepatitis," The American Journal of Gastroenterology, vol. 98, no. 11, pp. 2485-2490, 2003.

[106] A. C. Chan, "Partners in defense, vitamin E and vitamin C," Canadian Journal of Physiology and Pharmacology, vol. 71, no. 9, pp. 725-731, 1993.

[107] H. F. Ji and L. Shen, "On the mechanism of action of vitamin E for nonalcoholic steatohepatitis," Hepatology, vol. 53, no. 3, p. 1067, 2011.

[108] S. Yokohama, Y. Tokusashi, K. Nakamura et al., "Inhibitory effect of angiotensin II receptor antagonist on hepatic stellate cell activation in non-alcoholic steatohepatitis," World Journal of Gastroenterology, vol. 12, no. 2, pp. 322-326, 2006.

[109] S. Yokohama, M. Yoneda, M. Haneda et al., "Therapeutic efficacy of an angiotensin II receptor antagonist in patients with nonalcoholic steatohepatitis," Hepatology, vol. 40, no. 5, pp. 1222-1225, 2004.

[110] D. M. Torres, F. J. Jones, J. C. Shaw et al., "Rosiglitazone versus rosiglitazone and metformin versus rosiglitazone and losartan in the treatment of nonalcoholic steatohepatitis in humans: a 12month randomized, prospective, open- label trial," Hepatology, vol. 54, no. 5, pp. 1631-1639, 2011.

[111] K. Fujita, M. Yoneda, K. Wada et al., "Telmisartan, an angiotensin II type 1 receptor blocker, controls progress of nonalcoholic steatohepatitis in rats," Digestive Diseases and Sciences, vol. 52, no. 12, pp. 3455-3464, 2007.

[112] H. Kudo, Y. Yata, T. Takahara et al., “Telmisartan attenuates progression of steatohepatitis in mice: role of hepatic macrophage infiltration and effects on adipose tissue," Liver International, vol. 29, no. 7, pp. 988-996, 2009.

[113] H. Jin, N. Yamamoto, K. Uchida et al., "Telmisartan prevents hepatic fibrosis and enzyme-altered lesions in liver cirrhosis rat induced by a choline-deficient L-amino acid-defined diet," Biochemical and Biophysical Research Communications, vol. 364, no. 4, pp. 801-807, 2007.

[114] H. Nakagami, M. K. Osako, F. Nakagami et al., "Prevention and regression of non-alcoholic steatohepatitis (NASH) in a rat model by metabosartan, telmisartan," International Journal of Molecular Medicine, vol. 26, no. 4, pp. 477-481, 2010.

[115] M. Clemenz, N. Frost, M. Schupp et al., "Liver-specific peroxisome proliferator-activated receptor $\alpha$ target gene regulation by the angiotensin type 1 receptor blocker telmisartan," Diabetes, vol. 57, no. 5, pp. 1405-1413, 2008.

[116] E. F. Georgescu, R. Ionescu, M. Niculescu et al., "Angiotensinreceptor blockers as therapy for mild-to-moderate hypertension-associated non-alcoholic steatohepatitis," World Journal of Gastroenterology, vol. 15, no. 8, pp. 942-954, 2009.

[117] Y. Miura, N. Yamamoto, S. Tsunekawa et al., "Replacement of valsartan and candesartan by telmisartan in hypertensive patients with type 2 diabetes: metabolic and antiatherogenic consequences," Diabetes Care, vol. 28, no. 3, pp. 757-758, 2005.

[118] H. Schumacher and G. Mancia, "The safety profile of telmisartan as monotherapy or combined with hydrochlorothiazide: a retrospective analysis of 50 studies," Blood Pressure, vol. 17, supplement 1, pp. 32-40, 2008.

[119] L. Miele, V. Valenza, G. La Torre et al., "Increased intestinal permeability and tight junction alterations in nonalcoholic fatty liver disease," Hepatology, vol. 49, no. 6, pp. 1877-1887, 2009.

[120] H. Zhang, J. K. DiBaise, A. Zuccolo et al., "Human gut microbiota in obesity and after gastric bypass," Proceedings of the National Academy of Sciences of the United States of America, vol. 106, no. 7, pp. 2365-2370, 2009.

[121] G. Szabo, S. Bala, J. Petrasek, and A. Gattu, "Gut-liver axis and sensing microbes," Digestive Diseases, vol. 28, no. 6, pp. 737-744, 2010.

[122] R. Aller, D. A. De Luis, O. Izaola et al., "Effect of a probiotic on liver aminotransferases in nonalcoholic fatty liver disease patients: a double blind randomized clinical trial," European Review for Medical and Pharmacological Sciences, vol. 15, no. 9, pp. 1090-1095, 2011.

[123] M. Malaguarnera, M. Vacante, T. Antic et al., "Bifidobacterium longum with fructo-oligosaccharides in patients with non alcoholic steatohepatitis," Digestive Diseases and Sciences, vol. 57, no. 2, pp. 545-553, 2012.

[124] V. W.-S. Wong, G. L.-H. Wong, A. M.-L. Chim et al., "Treatment of nonalcoholic steatohepatitis with probiotics. A proof-ofconcept study," Annals of Hepatology, vol. 12, no. 2, pp. 256-262, 2013.

[125] Y.-Y. Ma, L. Li, C.-H. Yu et al., "Effects of probiotics on nonalcoholic fatty liver disease: a meta-analysis," World Journal of Gastroenterology, vol. 19, no. 40, pp. 6911-6918, 2013.

[126] Y. Zhang and P. A. Edwards, "FXR signaling in metabolic disease," FEBS Letters, vol. 582, no. 1, pp. 10-18, 2008. 
[127] C. Thomas, R. Pellicciari, M. Pruzanski et al., "Targeting bileacid signalling for metabolic diseases," Nature Reviews Drug Discovery, vol. 7, no. 8, pp. 678-693, 2008.

[128] S. Mudaliar, R. R. Henry, A. J. Sanyal et al., "Efficacy and safety of the farnesoid $\mathrm{x}$ receptor agonist obeticholic acid in patients with type 2 diabetes and nonalcoholic fatty liver disease," Gastroenterology, vol. 145, no. 3, pp. 574-582, 2013.

[129] B. A. Neuschwander-Tetri, R. Loomba, A. J. Sanyal et al., "Farnesoid X nuclear receptor ligand obeticholic acid for noncirrhotic, non-alcoholic steatohepatitis (FLINT): a multicentre, randomised, placebo-controlled trial," The Lancet, 2014.

[130] M. N. D. Di Minno, A. Russolillo, R. Lupoli et al., "Omega-3 fatty acids for the treatment of non-alcoholic fatty liver disease," World Journal of Gastroenterology, vol. 18, no. 41, pp. 5839-5847, 2012.

[131] D. G. Bouzianas, S. D. Bouziana, and A. I. Hatzitolios, "Potential treatment of human nonalcoholic fatty liver disease with longchain omega-3 polyunsaturated fatty acids," Nutrition Reviews, vol. 71, no. 11, pp. 753-771, 2013.

[132] L. Spadaro, O. Magliocco, D. Spampinato et al., "Effects of n-3 polyunsaturated fatty acids in subjects with nonalcoholic fatty liver disease," Digestive and Liver Disease, vol. 40, no. 3, pp. 194199, 2008.

[133] M. Capanni, F. Calella, M. R. Biagini et al., "Prolonged n-3 polyunsaturated fatty acid supplementation ameliorates hepatic steatosis in patients with non-alcoholic fatty liver disease: a pilot study," Alimentary Pharmacology \& Therapeutics, vol. 23, no. 8, pp. 1143-1151, 2006.

[134] N. Tanaka, K. Sano, A. Horiuchi et al., "Highly purified eicosapentaenoic acid treatment improves nonalcoholic steatohepatitis," Journal of Clinical Gastroenterology, vol. 42, no. 4, pp. 413-418, 2008.

[135] G. Fortin, "L-Carnitine and intestinal inflammation," Vitamins and Hormones, vol. 86, pp. 353-366, 2011.

[136] M. Romano, M. Vacante, E. Cristaldi et al., "L-carnitine treatment reduces steatosis in patients with chronic hepatitis $\mathrm{C}$ treated with alpha-interferon and ribavirin," Digestive Diseases and Sciences, vol. 53, no. 4, pp. 1114-1121, 2008.

[137] M. Malaguarnera, M. P. Gargante, C. Russo et al., "L-carnitine supplementation to diet: a new tool in treatment of nonalcoholic steatohepatitis - a randomized and controlled clinical trial," American Journal of Gastroenterology, vol. 105, no. 6, pp. 1338-1345, 2010.

[138] October 2014, https://clinicaltrials.gov/. 


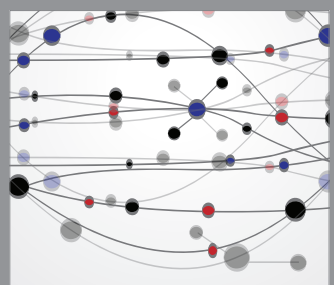

The Scientific World Journal
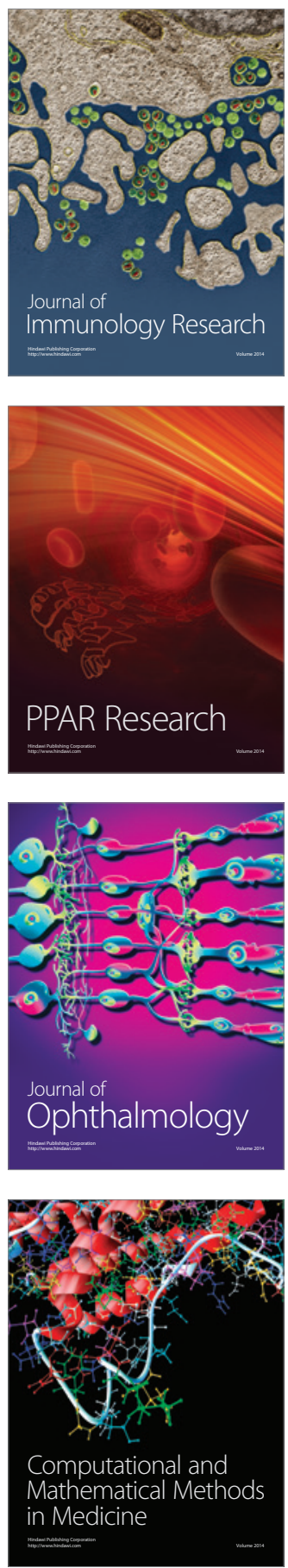

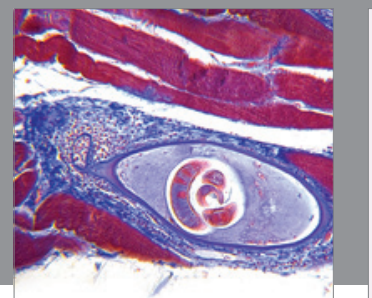

Gastroenterology

Research and Practice
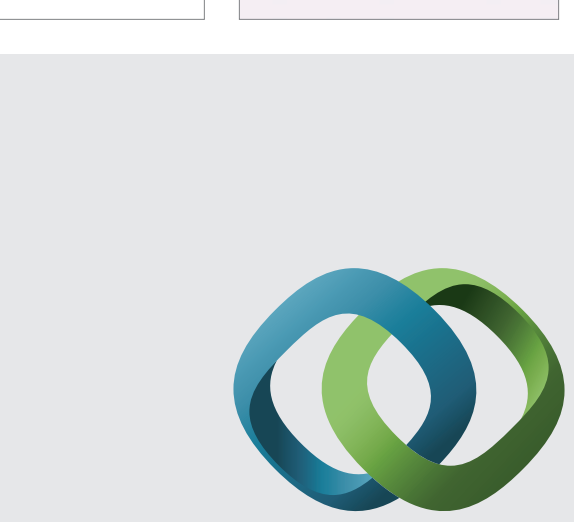

\section{Hindawi}

Submit your manuscripts at

http://www.hindawi.com
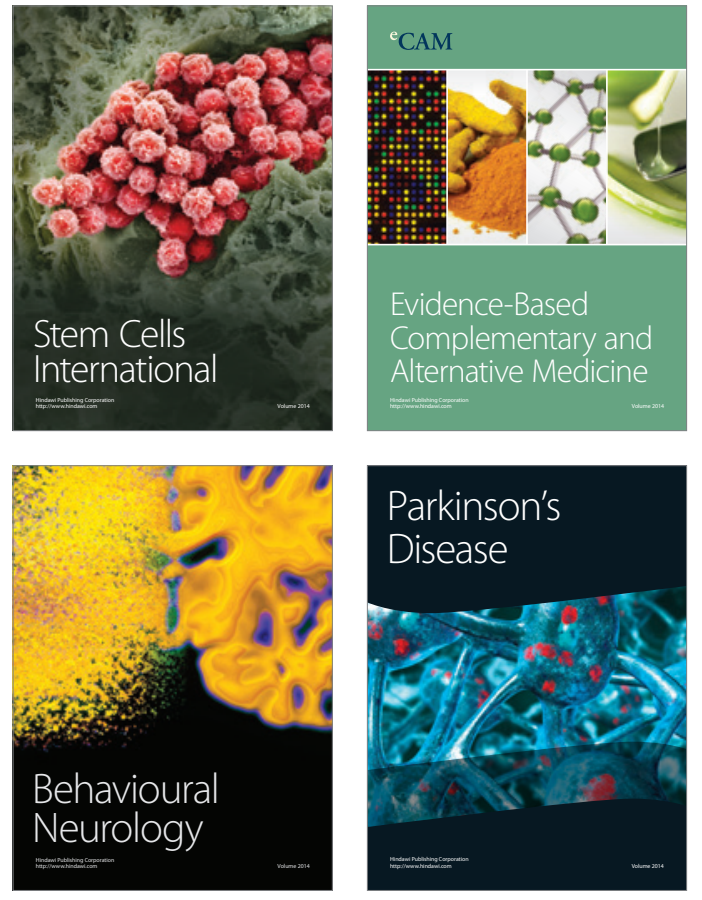
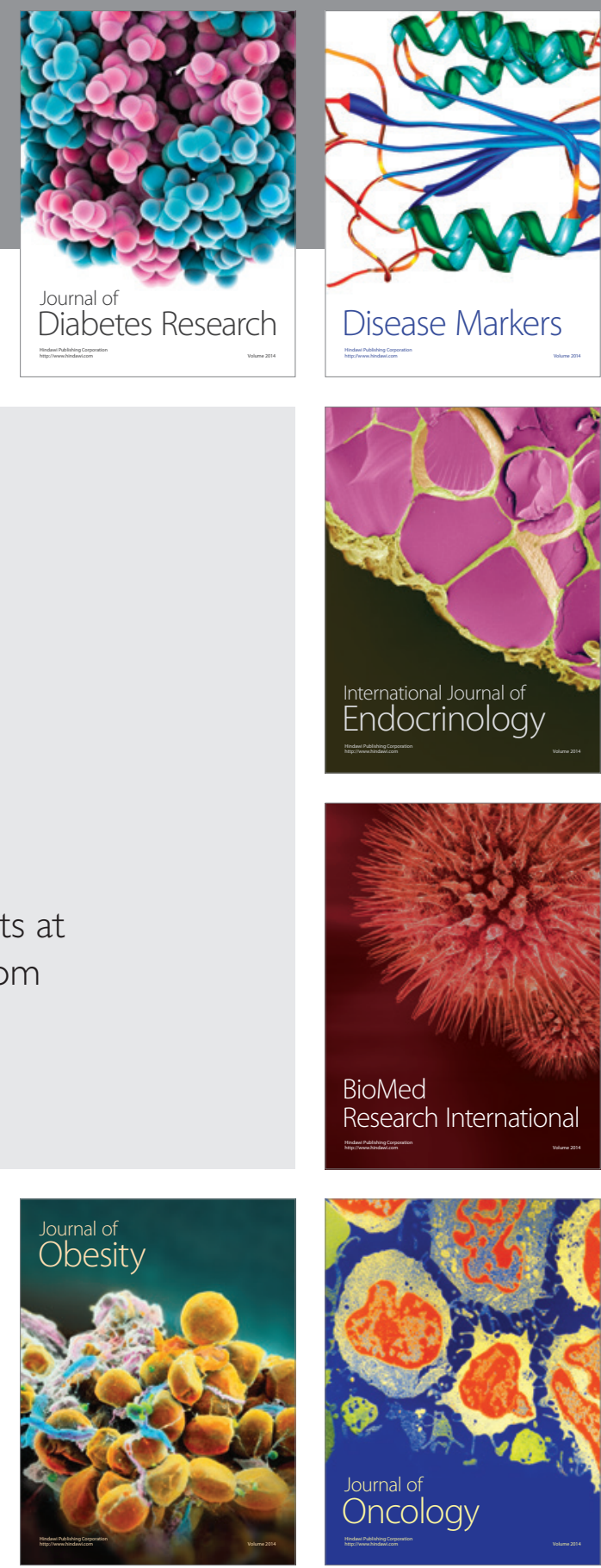

Disease Markers
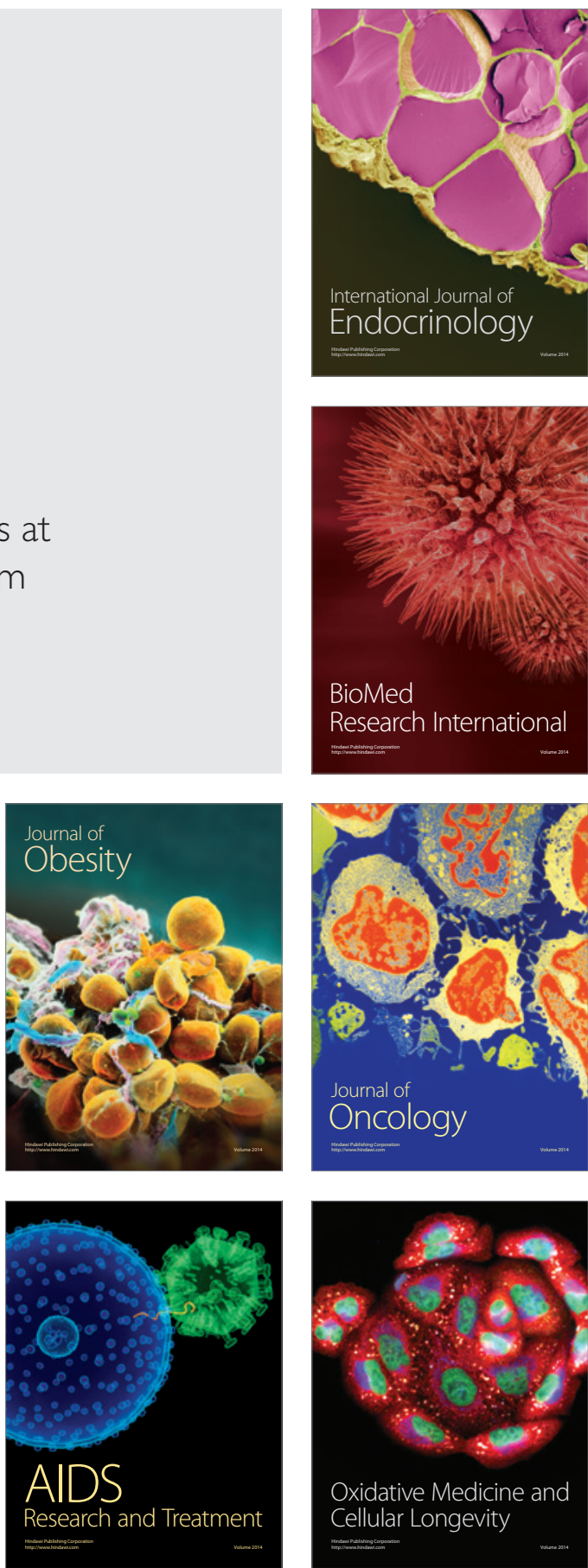